\title{
¿Cómo afecta a la economía de El Salvador la crisis de COVID-I 9?"
}

Entrevista a Edgar David Avilés

Director Ejecutivo

Asociación Salvadoreña de Intermediarios Bursátiles

El Salvador ha generado parte su financiamiento mediante la emisión de bonos para el desarrollo de proyectos que son previamente aprobados por la Asamblea Legislativa.

Previamente a la crisis ¿cuál era la evolución que tenían las emisiones de El Salvador que cotizan en los mercados internacionales?

En enero, los precios de los bonos de El Salvador se cotizaban arriba de la par (arriba del 100\%) y podían negociarse sin ningún problema. Por supuesto, hay algunas emisiones que son las más buscadas por los inversionistas $y$, generalmente, son las que tienen el vencimiento más a corto plazo, como el del 2023; y otras que son el parámetro para las que tienen más plazo de vencimiento, tal como la que vence en 2035. Pero en general, todas se estaban negociando con sobreprecio.

Para citar un ejemplo, el eurobono con vencimiento en 2035 se negociaba a 116\%; pero ya, a este día, se está negociando a $81.25 \%$, lo que significa una caída del $30 \%$.

Con la crisis del COVID-19, el gobierno de EI Salvador recibió la autorización de emitir 2,200 millones en deuda. Actualmente ¿cuál es la cotización de bonos salvadoreños en la crisis?

Los eurobonos de El Salvador empezaron a experimentar una baja en la cotización de sus precios, junto con los bonos de otros países emergentes. Pero, a medida que se fue profundizando la crisis y se empezaron a conocer las medidas que el gobierno aplicaría, y que estas necesitarían un financiamiento extraordinario, los bonos tendieron a bajar más, en comparación a los otros bonos de países emergentes.
La forma de verificar esta tendencia era comparar los bonos con fechas de maduración parecidas, entre nuestros bonos con respecto a los demás bonos emergentes. Antes de la crisis, un eurobono de 30 años estaba rindiendo entre $6.50 \%$ y $7.0 \%$; ahora la rentabilidad anda entre $10 \%$ y $10.50 \%$.

\section{El riesgo país es un elemento que define la tasa de} interés con la que se emite la deuda y es analizada por los inversionistas. ¿Cuál es el spread de riesgo de país que actualmente se tiene?

El spread que generalmente se toma es el de los bonos de los Estados Unidos. Por ejemplo, para el caso de la nota del 2029, se analiza contra el bono del tesoro de 10 años.

Antes de las crisis, el spread entre ellos era de 445 puntos básicos, y ahora está a 1066 puntos básicos. Llevándolo a términos de rentabilidad, antes de las crisis, el bono rendía $4.45 \%$, y ahora rinde $10.66 \%$.

Por otro lado, hay que tomar en cuenta el cambio de perspectiva que Fitch le acaba de hacer a las emisiones de El Salvador, pasando de "estable" a "negativa".

¿Cómo se espera que afecte al gobierno y a las empresas con respecto a tasas de interés la crisis del COVID-19?

Al gobierno lo afectará, ya que conseguirá financiamiento a tasas más altas que las que hubiese podido obtener en condiciones normales. Esto igualmente afectará a emisiones privadas, pero podría ser que, dependiendo del rubro o industria en el que la empresa intervenga, el fondeo pueda subir unos puntos más de los que normalmente le hubiese costado antes de la crisis. 
Asimismo, se debe tomar en cuenta que las emisiones de empresas locales generalmente se colocan en el mercado de valores local, y estas son adquiridas por inversionistas nacionales, en su gran mayoría; o por inversionistas panameños (hoy con la integración de ambos mercados).

Otro factor que pudiera verse afectado es la disminución de inversionistas con interés en estos títulos locales, debido a que tenderían a preservar un poco su liquidez.

Para verlo con ejemplos: antes de la crisis, las letes, que son títulos con duración de hasta un año, rendían $4.50 \%$, y después de la crisis, la rentabilidad alcanzada fue de $9.50 \%$. Es importante señalar que, desde que inició la crisis, no ha salido una emisión al mercado, como para tener un dato medible que sea real. Antes de la crisis, un emisor privado colocó a un año plazo, con tasa de $5.40 \%$; y después de la crisis, este mismo emisor negoció el mismo título en mercado secundario, a 9,50\% de rentabilidad y ya con menos de un año al vencimiento.

Cualquier emisor salvadoreño (entidad pública o privada) que necesite un financiamiento internacional tendría que pagar una tasa más alta de la que hubiera obtenido antes de la crisis.

La banca tiene liquidez al no estar colocando préstamos. ¿Puede iniciar una oferta con más baja tasa de interés que el mercado bursátil?

Es un poco prematuro para tener una opinión al respecto, ya que esto dependerá de muchos factores, y primero habría que ver cómo sería el desempeño de la economía en general, cuando todos los agentes económicos vayan integrándose a sus labores. Por otro lado, el sistema bancario tendrá que evaluar, como sistema, cuáles serían las políticas y directrices que seguirán después de una crisis tan inusual como esta.

\section{¿Cuáles son las perspectivas que a futuro son importantes considerar para El Salvador?}

Es muy importante que todos los agentes económicos de nuestro país y el gobierno trabajen de la mano para que las decisiones que se tomen en conjunto nos hagan seguir un camino que pueda lograr la reactivación del país en el menor tiempo posible, y con el menor impacto negativo para los que generan desarrollo en nuestro país. Por esto es trascendental que las decisiones que se vayan a tomar vengan acompañadas de un consenso de país, y que todos estemos conscientes de que esto podría implicar un gran esfuerzo. Pero teniendo la ruta de trabajo clara, se podrá llegar a que el impacto en nuestra economía no sea tan grande.

La reactivación de la economía pasa por qué tan pronto podría ser la reinserción de la actividad comercial, que ha permanecido inactiva. El tiempo y los incentivos o estímulos crediticios que se les puedan brindar. Es importante también que el país pueda conseguir facilidades en el financiamiento para palear los estragos causados por la pandemia y que ayudarán a la reactivación económica.
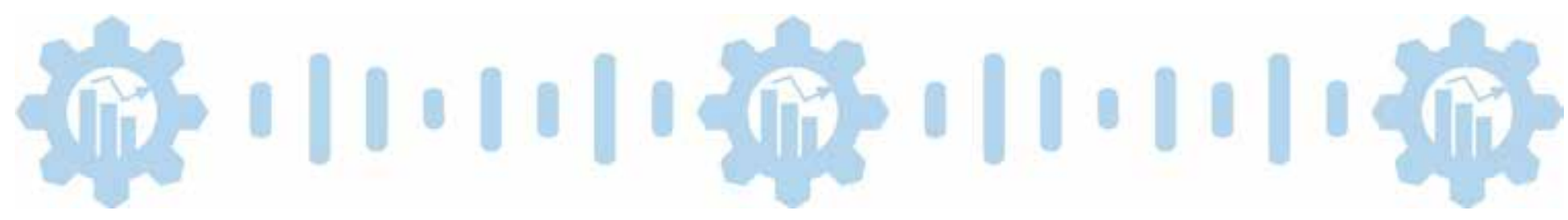